\title{
Model of Window Able to Create Regenerated Interior Cold Air Film
}

Mahmoud Majzoub ${ }^{1}$,

1 Architecture Engineer, Dammam, KSA (majzoob555@gmail.com)

\begin{abstract}
Building Engineering or Architectural engineering, is a major of science that deals with engineering aspects in buildings, such as structure, construction, site management, mechanical, electric, lighting, acoustic, and energy efficiency. Building engineering is one of unique sciences that is strongly connected with all other types of engineering majors. In addition, it is connected to human basic life directly, and its application is able to noticed easily. However, this research will focus on the field of energy efficiency and opening construction in buildings. The reason why building energy conservation grab more researchers 'attention is the fact of its relation with all other engineering aspects, and it is a building property that is very important along building life cycle. Currently humanity are living in world that energy market is biggest market in the world after weapons(Levy 2010). Nevertheless, energy in middle east is an important factor, especially when we know that country like Saudi Arabia, 75\% of inside energy consumption goes to residential buildings(Of and Audits n.d.). And the reason why these buildings consume that much refers to high usage of energy in building applications, and leak of using eco-friendly building material that able to reduce energy consumption in buildings.
\end{abstract}

Keywords: Window Performance, Cold Air Film, U-Value, Wet hey.

\section{Introduction}

$25 \%$ of heat loss occurs through building openings (A 2006), that means it's expected that controlling heat leakage from outdoor environment through window would save tangible ratio of energy consumption through air conditioning. In buildings, architects and designers prefer to use windows for natural light and for providing view for the users, however, the process of balancing between providing natural light, natural ventilation and view from a side, and the risk of having high cooling load materialize the nightmare of architects. Taking the previous facts in consider, it is the job of researchers to add flowers to this nightmare and put light at the end of the tunnel for designers, architect, engineers, and stakeholders. Providing a solution that reduce the damage of windows and curtain walls upon building thermal performance would be a corner stone for more research work in future to widen the features of windows implementation as part of a try to contribute in solution for the mentioned dilemma, this guide provides a suggestion for settle, as a model has concept spinning around the idea of producing regenerate air film along window slice, to increase its heat resistance. 


\section{Literature Review}

Barth et al (Barth, Memarian, and Park 2000) made study on Flexible Solar Control Window Films of various types for retrofit and original equipment (OEM), they aim to determine and highlight the importance and impact of flexible window film as tool to control heat gain through solar energy wet chemistry as well as vacuum coatings. they used WINDOW program software to compare window porotype patent by $3 \mathrm{M}$ company with standard $3-\mathrm{mm}$ window glass. They measure absorbance, transmittance, and reflectance. They found that such window would have low reflectance percentage almost equal to the base case moreover, they found a better performance in transmission and absorbance within short wavelength by $35 \%$ as an average.

R. Binions et al (Saeli et al. 2010) made study on applying Vanadium dioxide as base for intelligent glazing, it is one of the semiconductor metal which have structural rutile which in order would create a tangible impact on the optical properties and conductivity of electricity, so it is expected to have a positive impact on the thermal properties. They suggest also to use chemical vapor deposition produce thin films of vanadium dioxide. They used X-Ray to analyze the effect of the chemical vapor on thermal performance and the optical properties. They found temperature, color thermochromics properties are playing significant role in energy performance for such type of coating.

L. Boman et al (Boman et al. 2011) they made an investigation study on Low-E coating and its impact on energy performance on modern windows in cold climate. They test these modern windows and the impact of frame and spacer, they found that size window frame would have tangible impact on Low-E window performance. They used thermal modeling stimulation to find the effective thermal performance on complex window system. They found that there is need for multi-cavity glazing systems, and it is preferred to maintain neutral color which can't be applied in current Low-E coatings.

K. Iqbal et al (Iqbal et al. 2012) made study on anti-reflection coating for specified temperature rate, they prepared multi-layer thin film sorted by optical properties characterized structurally by spectrophotometer, an atomic force microscope. They found by $\mathrm{x}$-ray transmittance is between $60 \%$ and $75 \%$, and they didn't find a tangible difference in crystal structure and roughness of coatings which its value varies between 9 and $25 \mathrm{~nm}$ when it is exposed to temperature range of 150-650 Celsius. Using energy dispersive they characterize the thickness of the film. As a numerous result, energy scattered spectroscopy shows that the ratio between Silicon and Oxygen is 0.67:1.

M.Yazdanian \& J.H.Klems (Yazdanian and Klems n.d.) made study to measure exterior convective film coefficient for windows in low rise buildings. They used experimental approaches and theoretical models to make the compression. Nonetheless, this compression shows data don't match with the used model like ASHRAE/DOE-2 model. The experimental model based on MoWiTT shows film coefficient with varies of temperature range of the exterior surface. Regarding to the wind speed within the case study location they found that MoWiTT model can be valid with low rise building.

Alfred Brunger et al (Anon n.d.) made study on heat gain coefficient for windows which have insect screens. They made competitive measurement for on type of insect screen with base case double glazed window, nonetheless, this study was made with various of climate conditions. They found that insect screen could reduce U-value by $7 \%$ and SHGC by $46 \%$ in case of outdoor placement, and it can reduce U-value by $14 \%$ and SHGC by $15 \%$ in case of indoor placement. 
M. Lewis \& L. Parin (Bauer 2011) made study on prototype which have ability of vibration damping for the air film. They suggest to use such a methodology with two glazing layer separated with solid material, they also suggest it to be clear at all visible wavelengths. The developed model has gap filled with gaseous compound, and in the upper side of the frame, there is the damping machine which vibrating the one of the glazing panes. They found that such a method could create a turbulent air movement which could recycle the air and reduce its temperature, thus reduce the air film conductivity.

S. Wilson et al (Containing and Airlayer 2011) made study on model of window have a selective solar control film contain an air layer. The model has a silver coating which reflect solar radiation near to mid infrared ranges, because that silver has susceptible to oxidation, it turns to a black body, however, the oxidation rate is designed to be slow to acceptable rate, this silver layer could be located between to glass panes to reduce the oxygen to defusing through and reach the glass layer, and balances the rate of oxygen diffusion rate to stagnated acceptable level.

Min Li et al (Samaan et al. 1986) made study on of CuInS2 thin films by electrodeposition and sulfurization. They used X-ray diffraction to characterize film obtained, they also used scanning electron microscope (SEM), energy dispersive spectroscopy (EDS). They investigated the mixture of choline chloridehrea eutectic mixture on large windows, which are typically used. They found when compared with aqueous electrolytes, the large windows which work by electrochemical approach could have relatively high thermal stability of which allow the direct electrodeposition of $\mathrm{Cu}$-In precursor films, therefore scatters undesired rays depending on its wave length.

T.A. Gessert (The, Of, and Interpolymer 2020) made study to discuss three type of thin film PV technologies in united states. He characterizes the PV surface alloy to three categories depending on toxicity level, these three modules expected to generate majority of electric generated by PV in united states by 2030 . He uses literature review to estimate the amount of thermal performance of the PV film. He found that CdTe alloy have high electric generation rate with high performance air film insulation rate comparing with other two alloy samples.

As a summary it is clear that there were variety of trails in order find solution to reduce heat gain though windows without reducing natural lighting or natural ventilation. But yet there is still space for more progressing in such topic, which this guide tries to suggest solutions to add few drops to fulfill the gab. 


\section{Methodology}

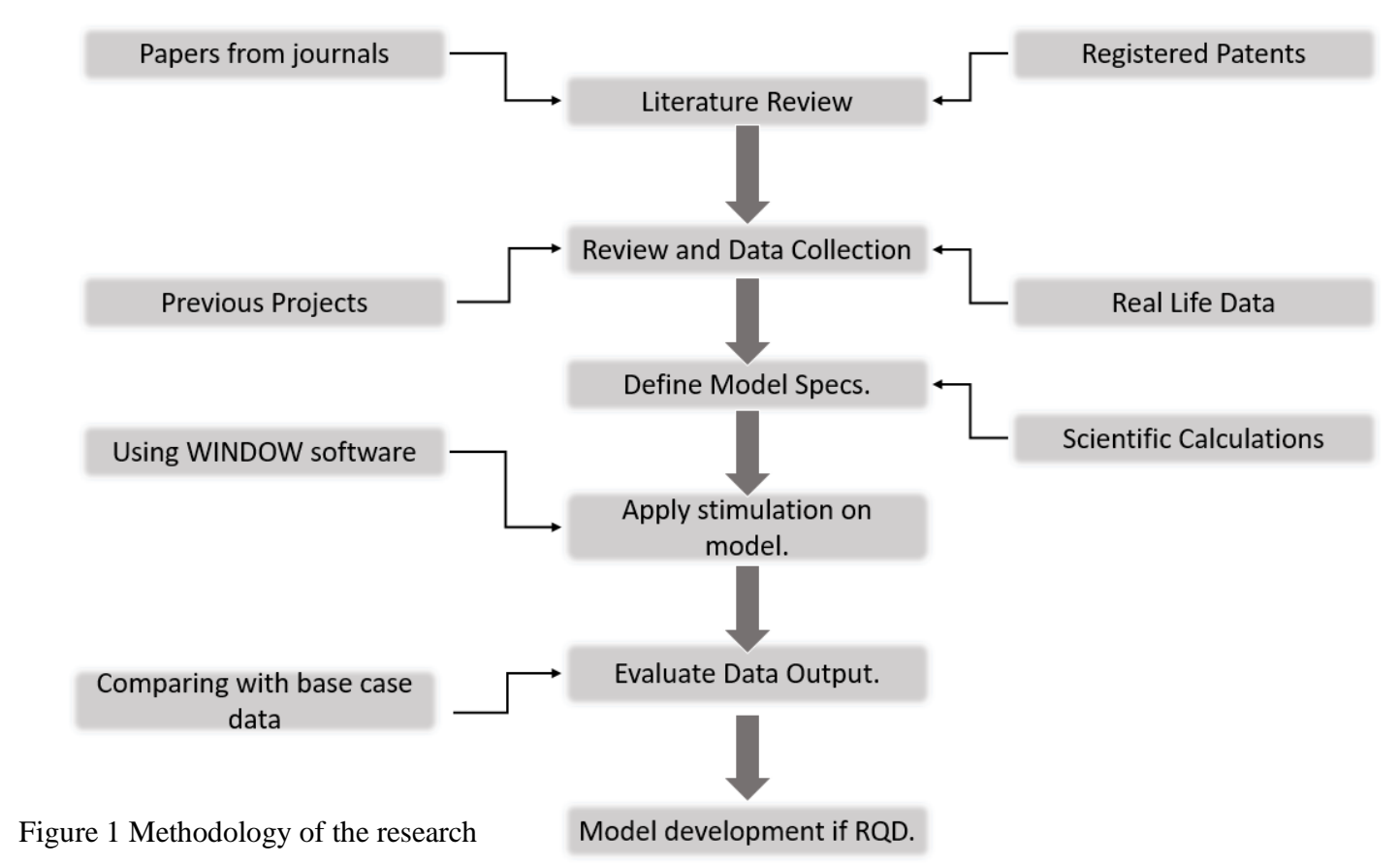

Figure above, shows the methodology plan which be used in this guide to accomplish the goal of the prototype. Its basic idea is to use the same concept of desert cooler, or traditional Muslim wind catcher to generate a cold air. In wind catcher, engineers and architects used to build it in high elevation to grab air, and then when hot air come to it, wet straw or sometimes water would cold it up and reduce air temperature.(Of and Audits n.d.)(Guide et al. n.d.) Then when air moves through wet hay, and become cold, it rotate inside building to absorb heat, and bring moist cold air. Unfortunately, this concept doesn't work in humid environment, especially in coastal areas. And it is not able to believe that people could use there building depending on these wind catchers, because of its low cooling efficiency comparing to its size.(Piraccini 2018)(Mobley 2001) On other hand, in middle of the summer, August and July, when temperature is more the 45 Celsius and humidity is more than $80 \%$, there would be no chance for air movement or prevailing winds to came through wet straw.(Of and Audits n.d.)

However, all of wind towers located in gulf countries now, are just for adding a traditional view to buildings, and it's nothing more than an architectural theme, although that gulf countries are in urgent need to such technology to reduce its huge demand to energy. On the other hand, desert cooler is used to reduce temperature in our rooms, it work by the same concept of wind tower. The only difference is that instead of depending on prevailing wind to bring air flow through hay, it uses a mechanical method to generate air flow, which represented in air blower. Air blower is the part that give air an enough impulse to move through cooling pad, Independently from outdoor condition. 


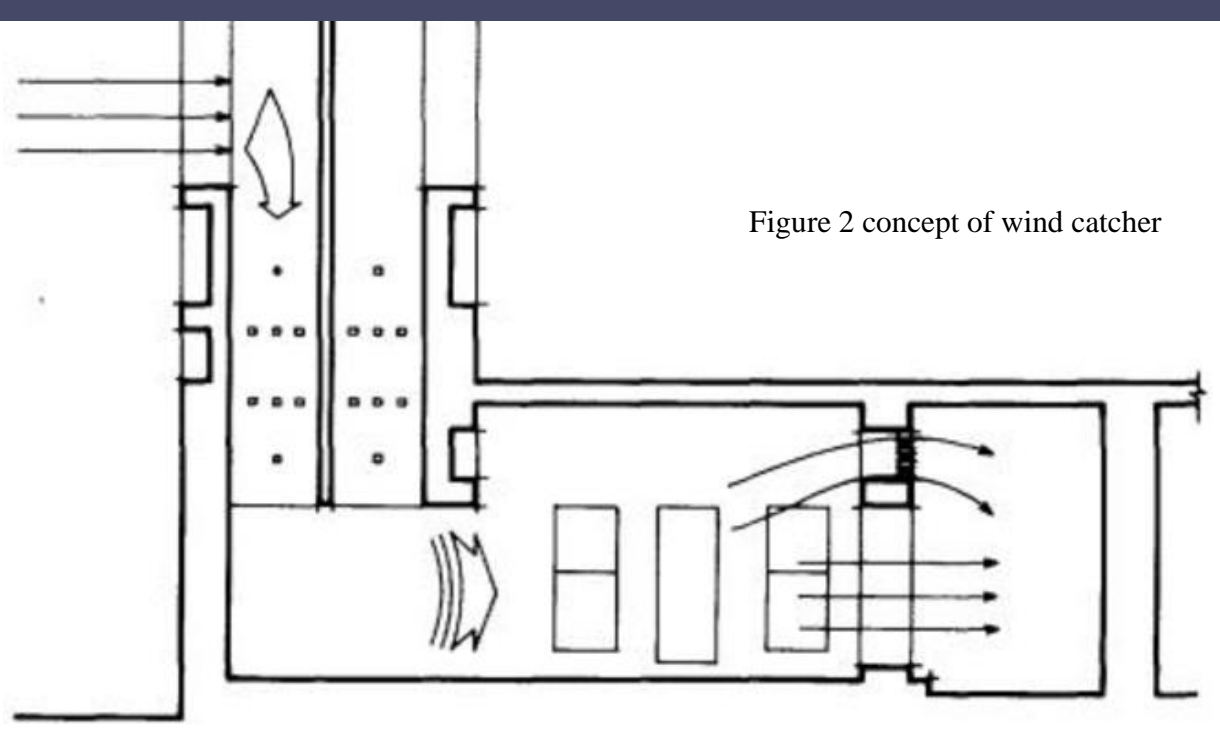

The figure 2 illustrates the main concept of evaporative air cooling (desert cooler). Which distinguished by its simple, cheap, easy, durable, and energy efficient component. Now, the question is, what is the connection between desert cooler and wind catcher from one side and this window prototype in the other side? Simply, this window model is inspired by these two technologies.

It works by locating an air room in the outer side of window frame which made from cast iron, when its temperature rises up due of sun radiation \& other outdoor conditions, the volume and pressure of air that located in air room will increase, and when it get an enough momentum to push it out from air room, it will get adequate kinetic energy to make air able to flow through cooling pad. When air came out from cooling pad it will become cold, then by using air fins we can easily control air to flow to inner side of window. Which is make an extra cold layer that able to increase window's heat resistance, and decrease the amount of U-Value to the limit.

The window is able to create an extra air layer without adding more glass surface, which decrease its cost. Also, this could make the window much lighter.This project is characterized by simplicity. Simplicity in everything starting from its component to its construction details to its manufacturing process and passing thought its concept. However, its simplicity doesn't prevent its importance, and its great affect in humankind life.

Metal cover have low specific heat, and it is one of the most important component in this prototype, its function is to grab solar radiation and transform it to air room, when it's going to get an enough energy to flow. Basically, it can be cast iron or aluminum.

Thin plastic slices pressure sensitive, is one of the project elements which it is important to control air flow form outdoor environment to air room and from air room to indoor space. When pressure increase in air room it opens due to pressure, allowing air to follow to wet hay. And when air room gets empty, its pressure decreases, comparing with outside atmospheric pressure, so this plastic slices opens due to atmospheric pressure allowing outdoor air to flow to fill air room, which important to let the invention works because without guarantying air flow the cycle won't work efficiently. Basically, any type of flexible then plastic or PVC would be useful. On other word when pressure in one side is greater than the other side of plastic slides, they will dent to the side of low pressure side. This dent will open a gap letting air to flow. 
Eventually, wet straw it role that when air flow from air room to indoor space, there is going to need a material that reduce air temperature, because air is heated in air room. And you can't let air get inside with reaches 70 cicelies. So that why we use wet straw to make air cold and wet, to cool the place and reduce heat transition, and decrease $\mathrm{U}-$ Value.

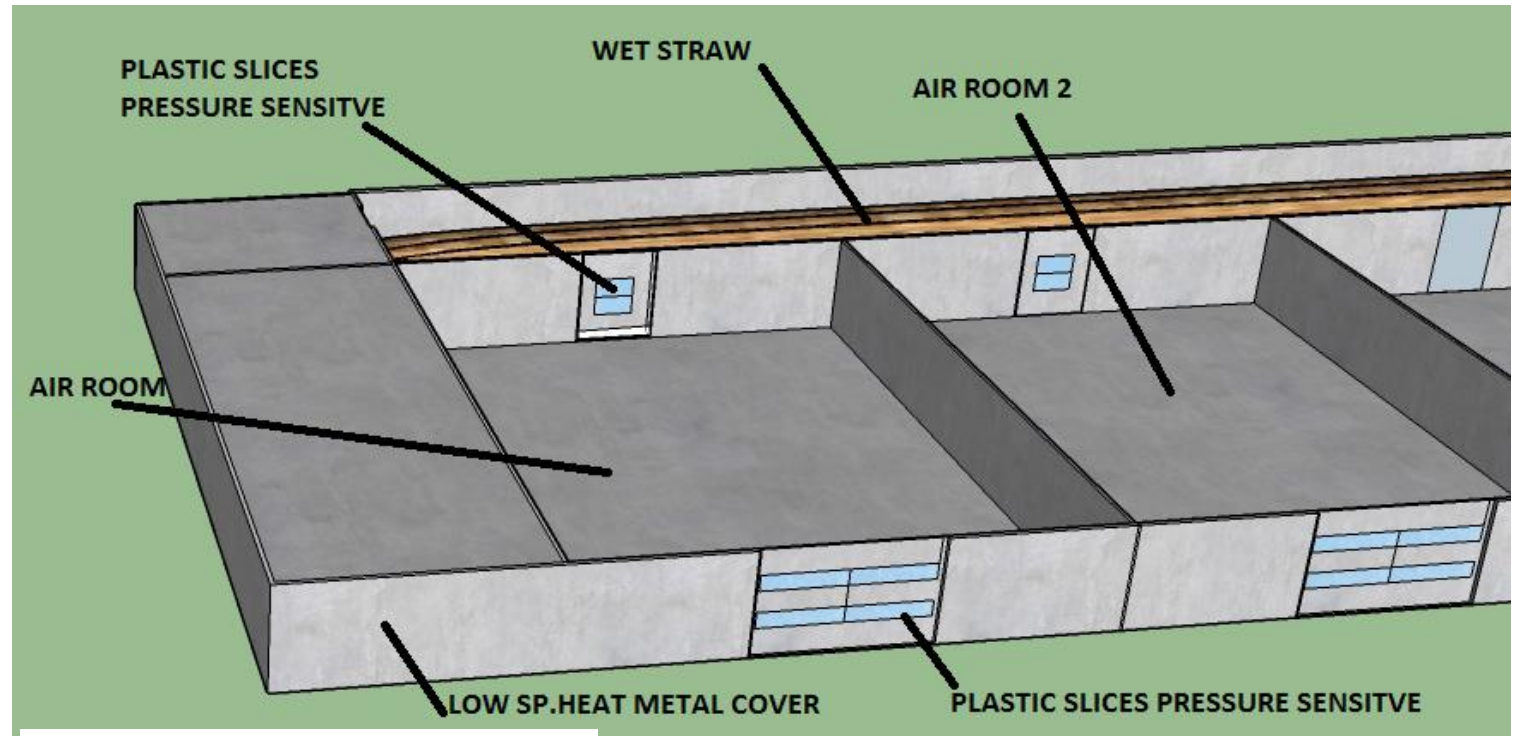

Figure 3. Frame air room components

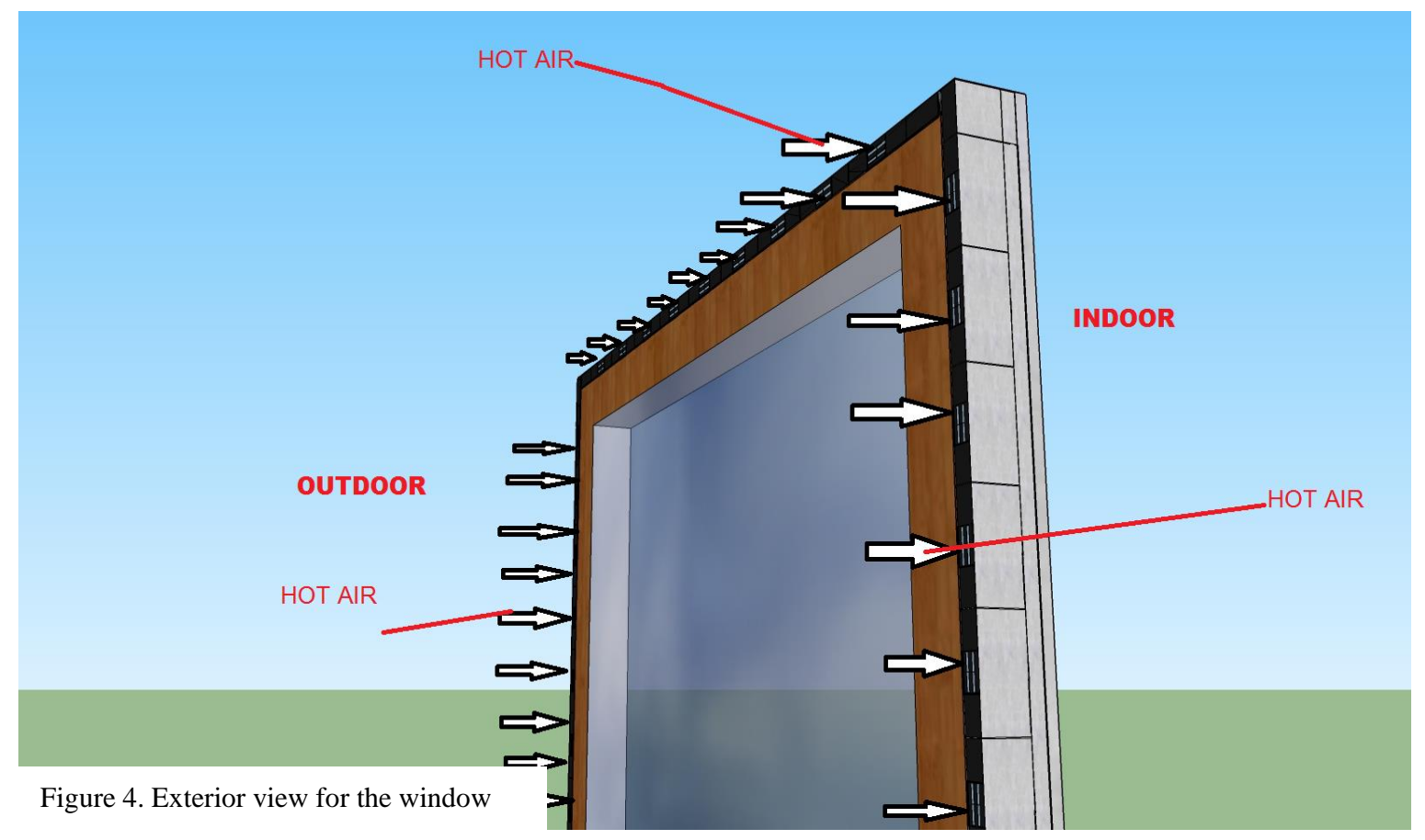

After mentioning the three project's components, explaining its working method would be much easier. When sun radiation sways on windows, its frame warm up, so we invest this radiation to heat air room that is located in window's frame. When air room temperature rises up its pressure increases then gives air an enough kinetic energy to flaw. And when air flow it opens the plastic slices pressure sensitive and get along with wet hay. When hot air flows throw wet hay its temperature decreases and become cold enough to resist. Then, there is fins to control air flow direction. These fins guide air flow to the direction of glass surface. 


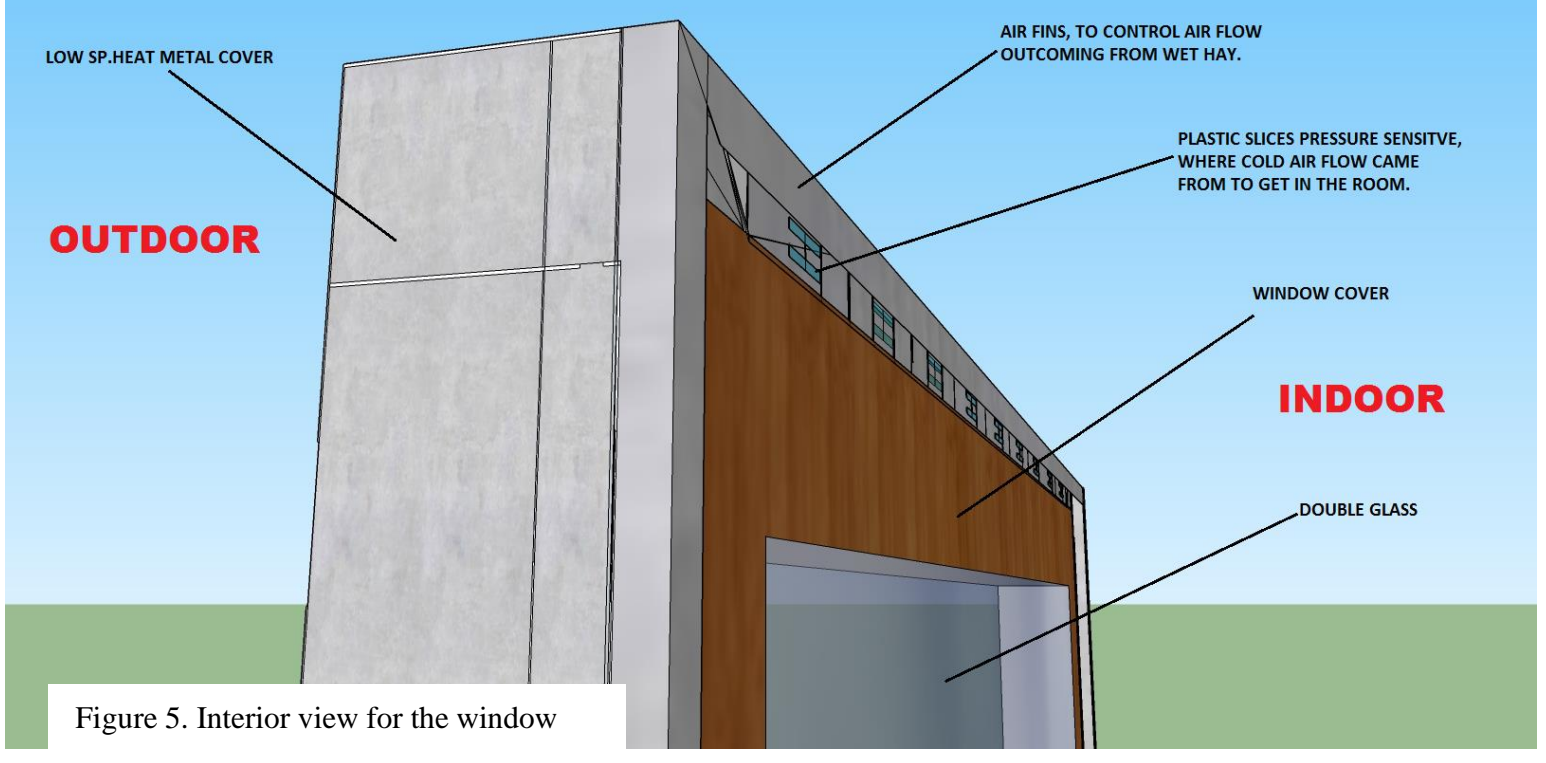

The result is continuous layer of cold air without extra glass layer that is able to increases windows heat transmission resistance by $50 \%$. However, when air room is out of air, its pressure decreases comparing with outdoor pressure - atmospheric pressure -, so plastic slice, which located in the front will dent-openallowing outdoor air to fill air room again, and when outer pressure balanced with air room pressure plastic slices close, to start heating operation. And the cycle continues. So, we can understand that target is to create an extra air resistance layer, not to make inner side of glass cold, although that is happening but is not something worth to create for it. However, it's important to mention that is as much as heat outside is high as much it's going to generates a cold air, and therefore increase its resistance. In other word, this window heat resistance is directly proportioned with outdoor temperature.

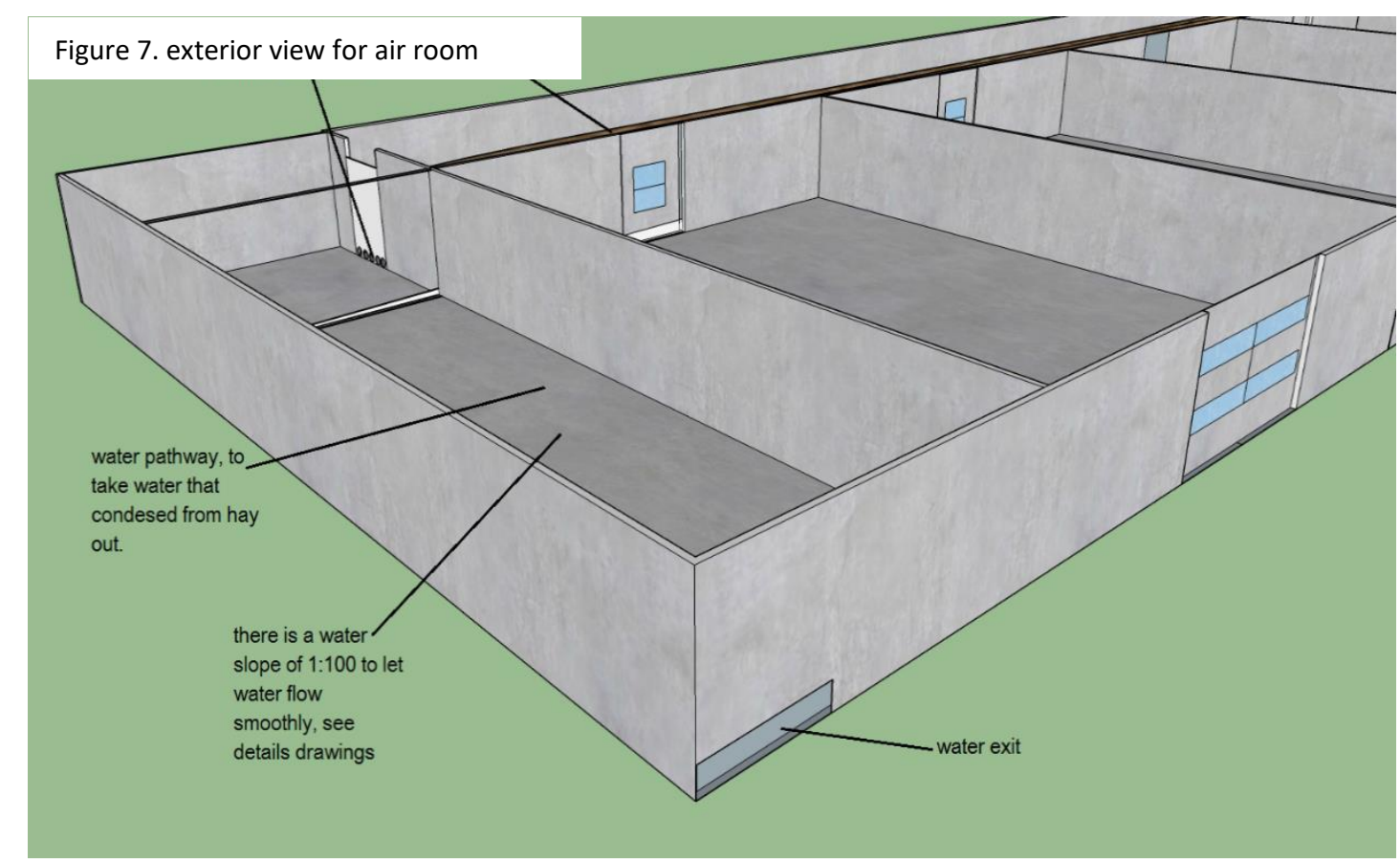

In the figure 6, which is represents the inner side of window, we can notice air fins, which are important to orient air flow in the right direction that create a separate layer that works as heat isolation. when this 
air layer warms up another cold air layer will replace the old one to increase resistance efficiency. In the figure below, a general view of outside perspective, that how is going to look in the building elevation. Seeing outside perspective carefully, we notice that metal cover has black paint, which important to grab most sun radiation, to heat air so fast. Black color has ability to seduce radiations because of its wave length. However, is important to mention that air flow came from the three sides of window. There is no air flow from down side window, because this project can't afford the load of window presently.

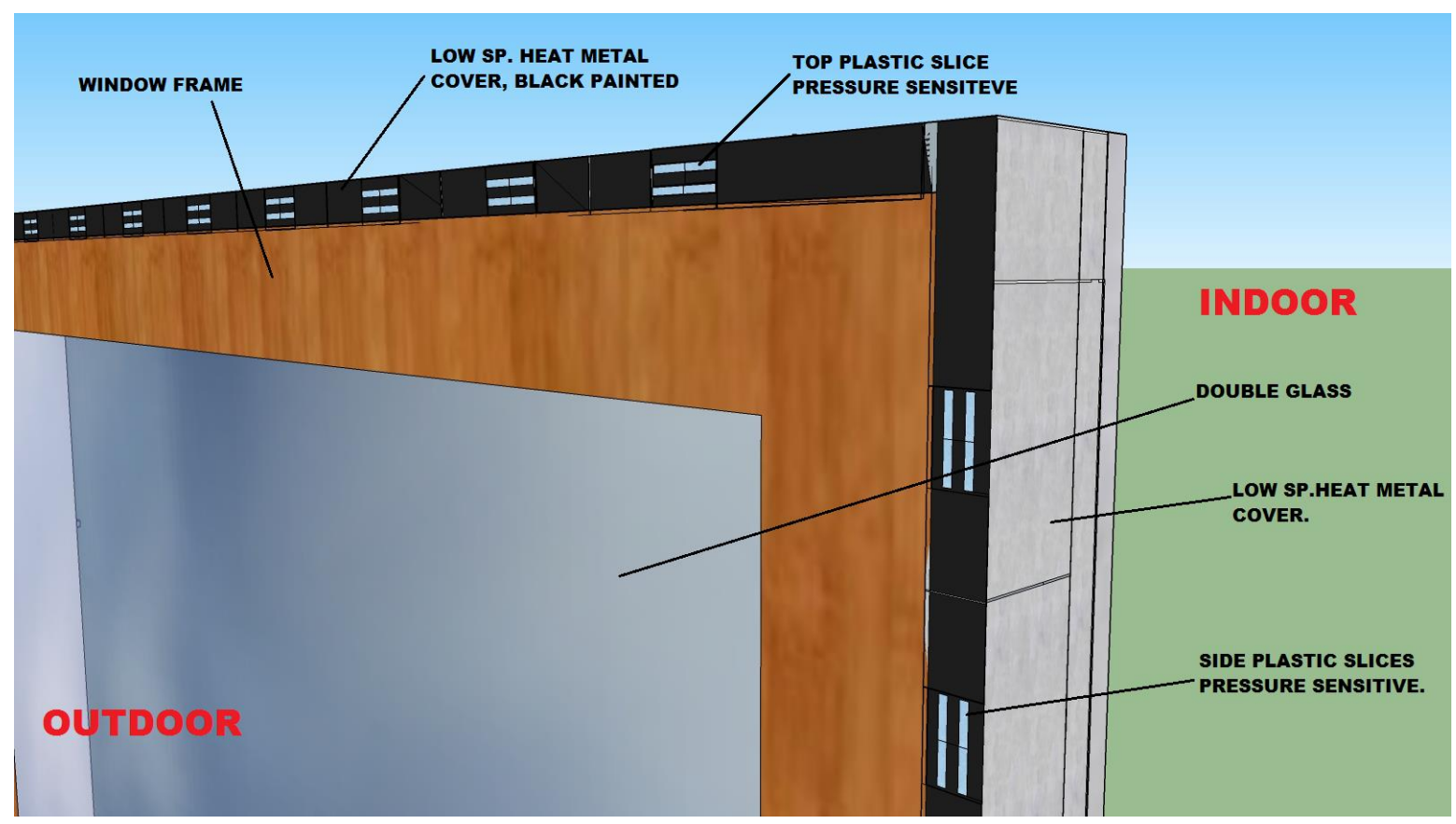

In pic.7 it can be noticed how hot air came from outdoor environment through plastic slices to fill air room due pressure difference. Figure.12 deals with such an important dilemma, which taking out condensate water. However, the surface that hold wat hay and water pathway both are slanted surface, for water flow (see drawings). And it is important to mention that supplying hay with water is going to from drainage HVAC cooling system. 


\section{Results and discussion:}

\subsection{Scientific calculations:}

The aim of these calculation is to find air characteristics Assuming that window frame is square $1.2 \mathrm{~m}$ wide air room section is $0.15 \mathrm{~m} \times 0.05 \mathrm{~m}$. So its volume:

$120 \mathrm{~cm} \times 5 \mathrm{~cm} \times 15 \mathrm{~cm}=9 \times 10^{3} \mathrm{~cm}^{3} \approx 0.009 \mathrm{~m}^{3}$

$\rho=\frac{v}{m} \rightarrow v=\rho m \rightarrow v=0.833 m$

$0.009=0.833 m \quad \therefore m=0.0108 \mathrm{~kg} \approx 10 \mathrm{~g}$

From Gay-Lussac's law which states that The pressure of a gas of fixed mass and fixed volume is directly proportional to the gas's absolute temperature.

$\frac{p 1}{T 1}=\frac{p 2}{T 2} . \quad$ where $p 1$ is atm pressure

$=101.3 \mathrm{KPa}$. and room tempreture is $25 \mathrm{C}$ and outer frame tempreture is $70 \mathrm{C}$

$\frac{p 1}{T 1}=\frac{p 2}{T 2} \rightarrow \frac{101.3 \mathrm{KPa}}{25}=\frac{p 2}{75}$

$p 2=\frac{101.3 \times 70}{25}=283.64 \mathrm{KPa}$

The Combined Gas Law or General Gas Equation is obtained by combining Boyle's Law, Charles' Law, and Gay-Lussac's Law. It shows the relationship between the pressure, volume, and temperature for a fixed mass (quantity) of gas:

$\frac{p 1 v 1}{T 1}=\frac{p 2 v 2}{T 2}$

$\frac{101.3 \times 0.009}{25}=\frac{283.6 \times v 3}{75}$

$V 2=\frac{101.3 \times 0.009 \times 75}{25 \times 283.6}=9.644 \times 10^{-3} \mathrm{~m}^{3}=9644 \mathrm{~cm}^{3}$

Now after we have find:

- air volume inside air rooms. - the volume of the air after heating.

- gas pressure after heating.

So the goal now is to find:

- air flow velocity - amount of air flow (discharge)

Finding Discharge:

$\rho 1 A 1 V 1=\rho 1 A 2 V 2=M=$ CONSTANT . air densty is contant

AIR MASS IN = AIR MASS OUT $=$ CONSTANT $=10 \mathrm{~g}$ 
$A 1 V 1=A 2 V 2=1 \times 10^{-2} \mathrm{~kg}$

$0.05 \times 1.2 \times \mathrm{V} 1=1 \times 10^{-2} \rightarrow \mathrm{V} 1=0.167 \mathrm{~m} / \mathrm{s}$

$0.05 \times 1.2 \times 0.167=0.04 \times \mathrm{V} 2=1 \times 10^{-2} \mathrm{~kg}$

$\therefore V 1=0.25 \mathrm{~m} / \mathrm{s} \approx 0.9 \mathrm{~km} / \mathrm{h}$

so Discharge will equal to: $Q=A \times V$

$0.04 \times 0.25=0.01 \mathrm{~m}^{2} / \mathrm{s}=10 \mathrm{l} / \mathrm{s}$

These calculation was done assuming that air opens area is $4 \mathrm{~cm} 2$

and the length of the window is $1.2 \mathrm{~m}$, so there will be 10 openings, the distance between each one is $12 \mathrm{~cm}$. Therefore, each open have $11 / \mathrm{s}$ discharge.

$\rho$ air $=1.225 \frac{\mathrm{kg}}{\mathrm{m}^{3}}$. air spaciefic heat $=\omega=\frac{m \times g}{\text { volume of fluid }}$

$\omega=\frac{(0.01)(9.8)}{(0.09)}=1.088$

spaciefic heat volume $=\frac{\text { volume }}{\text { mass }}=\frac{0.09}{0.01}=9 \mathrm{~m}^{3} / \mathrm{kg}$

Reynold number $=\frac{V D}{v}=\frac{(0.04)(0.167)}{2 \times 10^{-5}}=344$

Now, we have to know what is going to be the temperature of out coming air which passed through wat hay, in other words, the amount of heat exchange between hot air and wet straw.

Assuming that:

1-There is no work involved.

3 -Kinetic energy is negligible.

2-Potential energy is negligible.

$4-$ Heat transform is zero.

5- Plastic slices pressure sensitive opens when air temperature is 70 Celsius.

6-Wet hey water temperature is 10 Celsius.

$Q=m c \Delta T=0.01 \times 1.005 \times(70-25)=0.45 \mathrm{~J}$

Energy absorbed by water = Energy released by air

$(m c \Delta T) w=(\operatorname{mac} \Delta T) a$

$\frac{10}{1000} \mathrm{~kg} \times 4186^{\mathrm{J}} / \mathrm{Kg} \mathrm{C}^{0} \times(\mathrm{T} 2-10)=\frac{10}{1000} \mathrm{~kg} \times 1.005 \times(70-25)$

$(41.86)(T 2-10)=0.425 J$

$T 2-10=0.01 \quad \therefore T 2=10.018^{\circ} \mathrm{C}$ 
In the last but not least, U-Value Double Glass Clear Window will be found by stimulation, by entering window specification and the additional air film characteristics generated by prototype. Stimulation is done using WINDOW7.7 software.

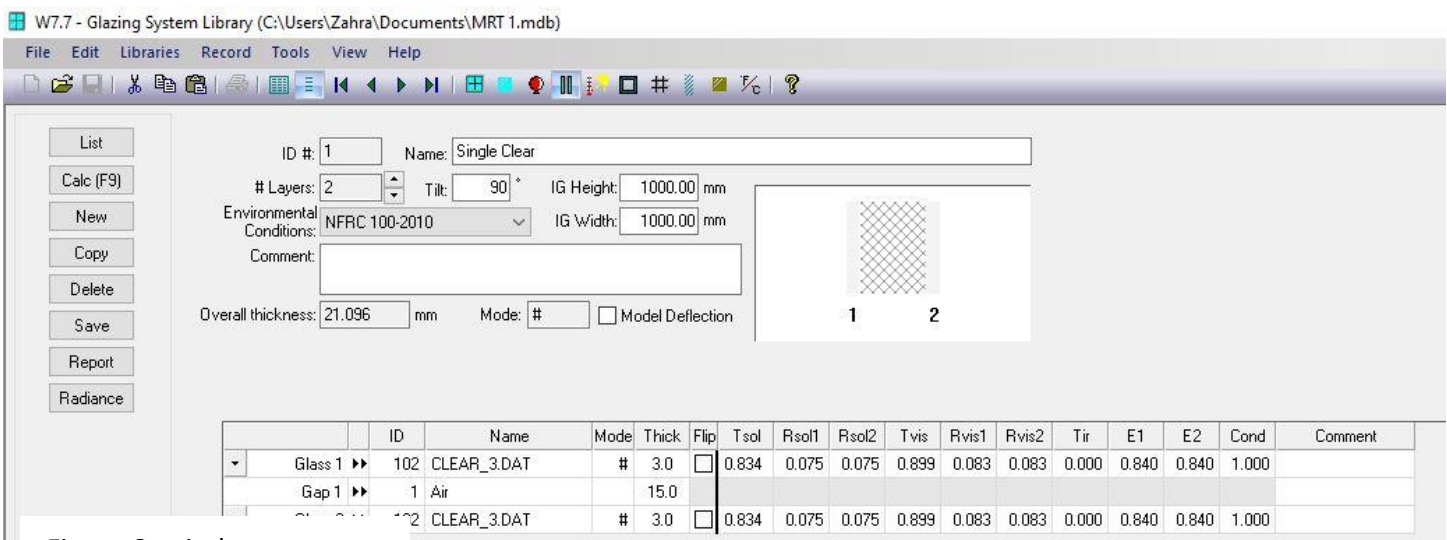

Figure 8. window specs.

Figure above show the glass sample details and specs, noticing that the test sample will be double glazing with $15 \mathrm{~mm}$ air gab. There will be two samples, one standard double glazed which it U-value is 3.63, and double glazed with added air layer which is $U$-value will be calculated during this process.

田 W7.7 - Environmental Conditions Library (C:\Users \Public \LBNL\WINDOW7.7 W7.mdb)

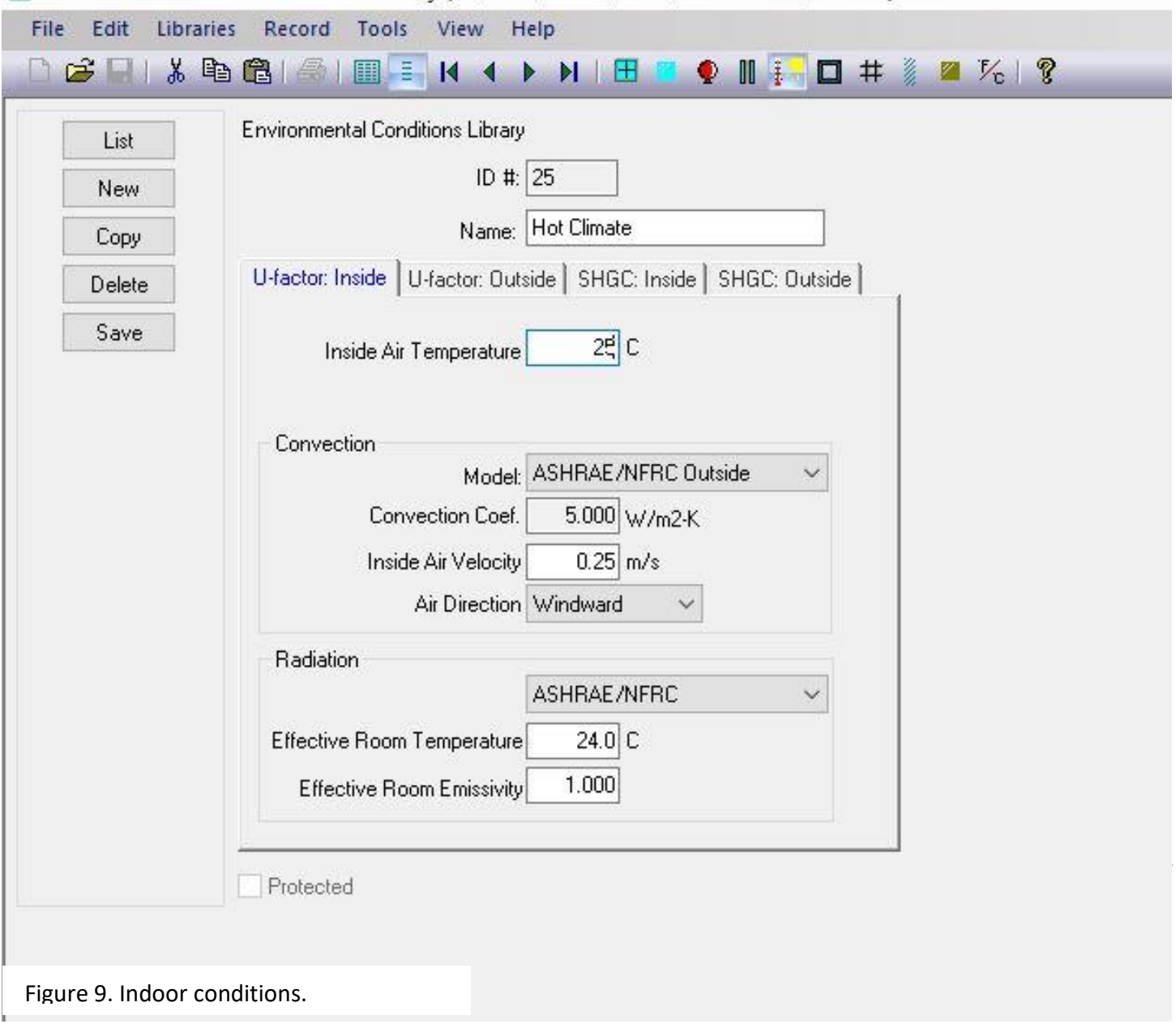




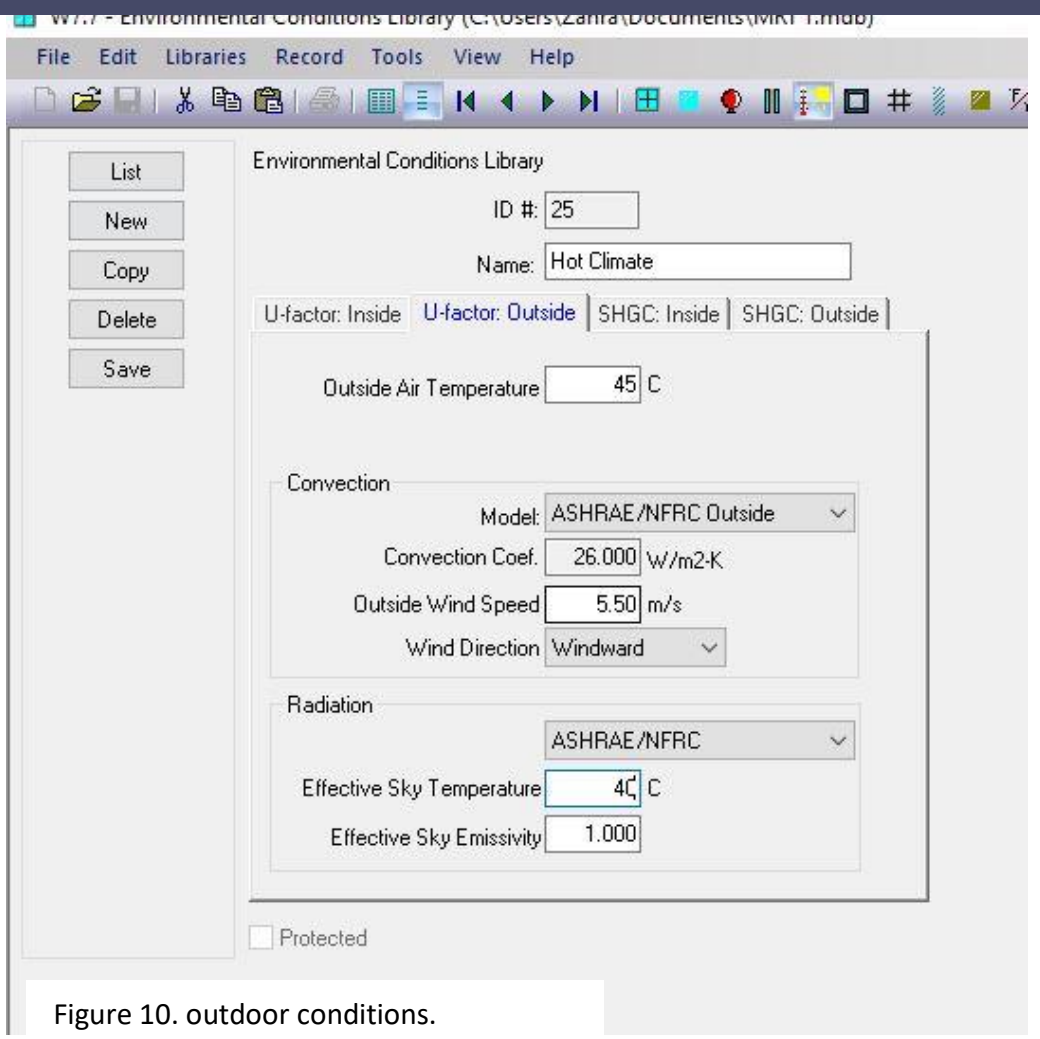

田 W7.7 - Gap Library (C:)Users Public LLNLLWINDOW7.7WW7.mdb)

File Edit Libraries Record Tools View Help

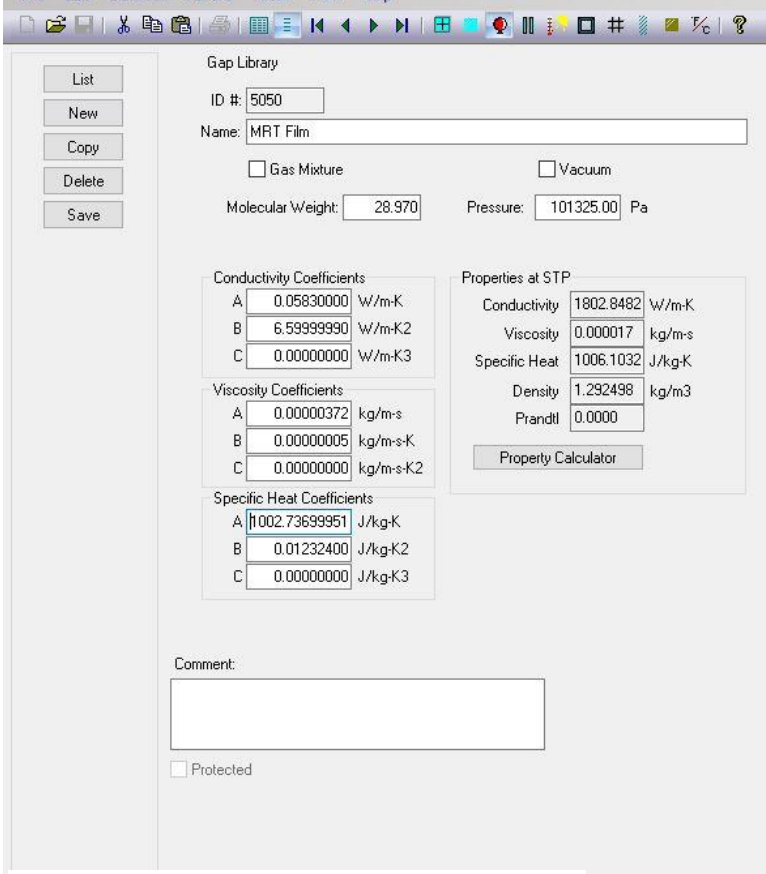

Figure 11. air film specs 
TABLE 8.7

Convection Coefficients for Air at Various Surfaces

(From ASHRAE Handbook 1981 Fundamentals, Table 5, p. 2.12;

Table 6, p. 2.15; [8.1] Min. T.C., Schutrum, L.F., Parmelee, G.V., and Vouris, J.D., ASHRAE Transactions, 1956, 62, pp. 343-50 [8.11]

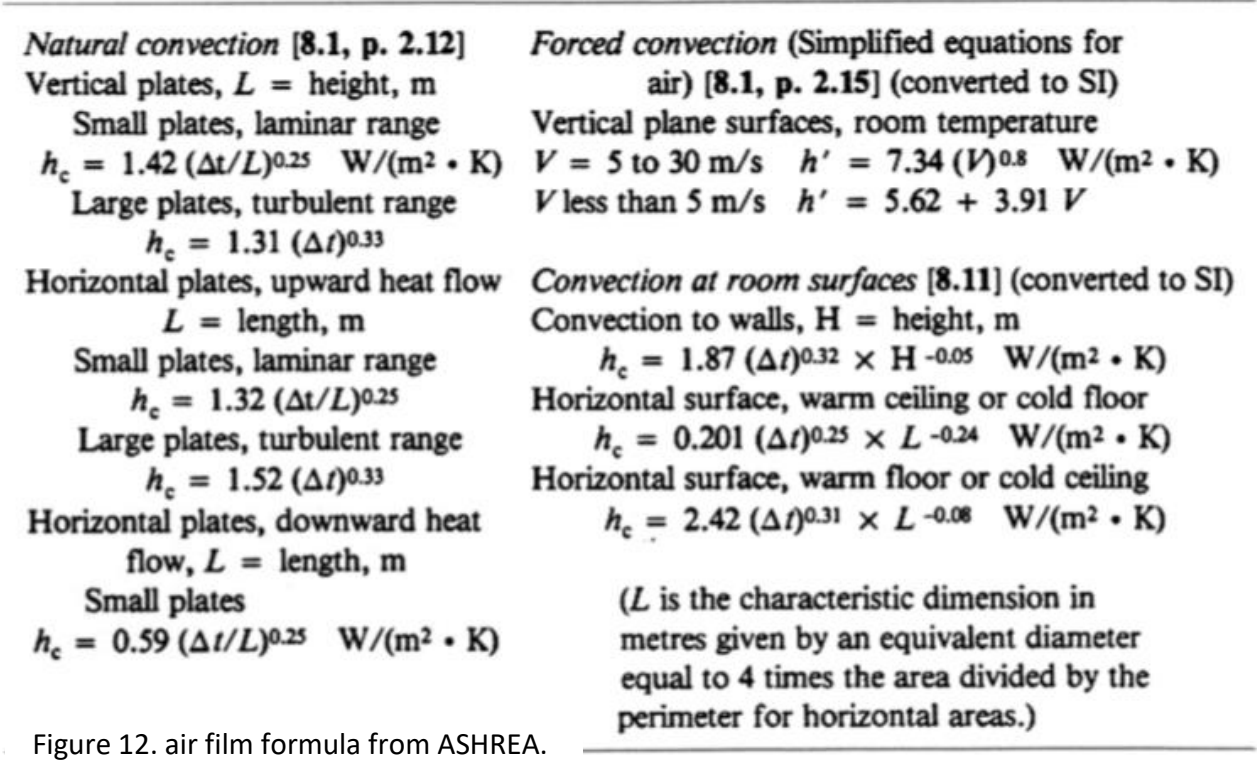

The figure 10 shows the temperature condition, which is 45 Celsius, where figure 12 shows the input air characteristics found by calculation which is air film conductivity.ASHREA table above shows the equation which heat conductance of generated air film which is

$$
\begin{aligned}
& h=5.62+3.91 V, \quad h=5.62+3.91(0.25)=6.6 \frac{w}{m^{2} k} \\
& R=\frac{1}{c}=\frac{1}{6.6}=0.15 \mathrm{~m}^{2} \mathrm{k} / \mathrm{w}
\end{aligned}
$$


Double glass U-Value is 3.63 ( From WINDOW), and Double glass U-Value for the tested prototype is 3.381 as appears in the previous figure.

Reduce of U-Value $=\frac{3.63-3.381}{3.63} \%=6.85 \%$, So, this project reduces heat transfer through double glass window by $6.85 \%$.

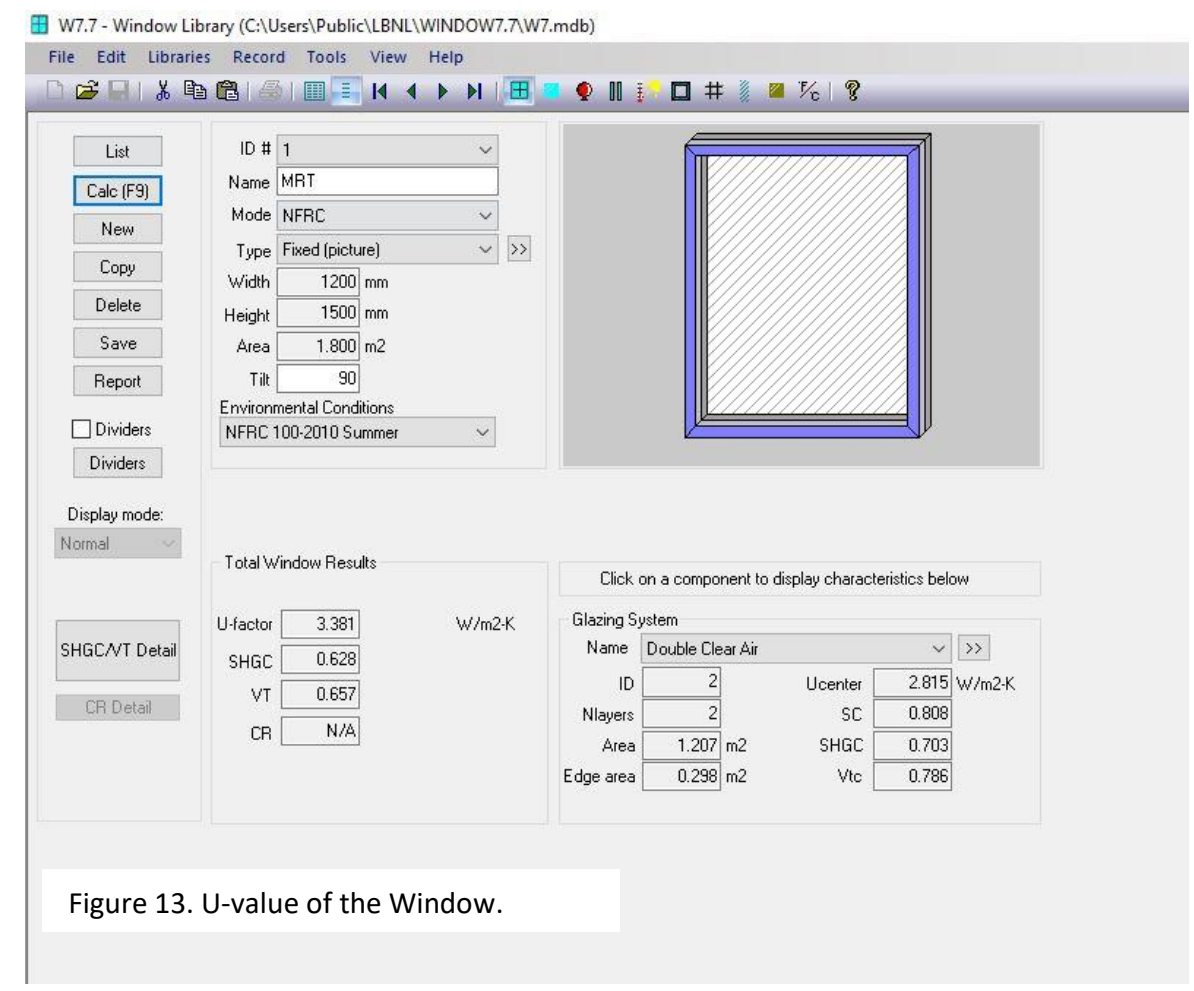

\section{Conclusion:}

This guide suggests a method to reduce heat gain through window, by using solar radiation though concept of desert cooler or wind catcher. Nonetheless, making a model and apply tests and experiments would be essential to define the practicality of the model. These calculation and stimulation are just the first finger of one foot, so it can't be considered as one step. It is expected to find more cons or pros in this concept when apply experiments on manufactured model.

Applying stimulation on window according to the calculated specifications and air characteristics, shows that it is expected to reduce heat gain by $6.85 \%$ for double glazed window, and the factors which could determine the feasibility of this number is type of building, window to wall ratio, and the of cost applying the idea. Regarding that it is a new idea, there is lot of gabs required to be fulfilled, and physical experiment would be the filler for sure. 


\section{References:}

A, Ê. Û. Ũãö. 2006. "Chapter $1 \hat{A}^{2}$ aIl Chapter $1 \hat{A}^{2}$ aq." 1-21.

Anon. n.d. "B30b569b44c78116cbedcbab12b23380.Pdf."

Barth, S., H. Memarian, and Canoga Park. 2000. "Solar Control Window Films - A Historical and Technological Perspective."

Bauer. 2011. “(12) United States Patent.” 1(12).

Boman, L., J. Meade, C. Stoessel, R. W, Southwall Technologies, and Palo Alto. 2011. "Impact of Thin Film Coatings on the Performance of Highly EnergyEfficient Windows." 452-56.

Containing, Filmi, and A. N. Airlayer. 2011. “(12) Patent Application Publication (10) Pub. No.: US 2011/0010994 A1.” 1(19).

Guide, Cibse, The European-, Energy Performance, Buildings Directive, Energy Performance Certificate, Display Energy Certificate, and This Guide. n.d. "1.1.2 Other CIBSE Publications." 1-10.

Iqbal, K., A. Maqsood, M. Mujahid, and M. H. Asghar. 2012. "Characterization and Preparation of Anti-Reflection.” 327-37.

Levy, Sidney M. 2010. “Green and Sustainable Buildings.” Construction Process Planning and Management 223-49.

Mobley, R. Keith. 2001. “The Role of the Plant Engineer.” Plant Engineer's Handbook 13-15.

Of, Types, and Energy Audits. n.d. "Energy Auditing and Accounting."

Piraccini, Stefano. 2018. Building Envelope.

Saeli, Manfredi, Clara Piccirillo, Ivan P. Parkin, Russell Binions, and Ian Ridley. 2010. "Optimisation of Thermochromic Thin Films on Glass; Design of Intelligent Windows." Advances in Science and Technology 75:79-90.

Samaan, A. N. Y., S. M. Wasim, A. E. Hill, D. G. Akmour, and R. D. Tomlinson. 1986. "Preparation and Properties of CuInS2 Thin Films Deposited by RF Sputtering." Physica Status Solidi (A) 96(1):317-24. 
The, Tudies O. N., Orphology Of, and The Interpolymer. 2020. "S Tudies on the F Ilm M Orphology of Pmaa and Its I Nterpolymer a Dducts.” 2(2007):111-18. Yazdanian, M., and J. H. Klems. n.d.

"MeasurementoftheExteriorConvectiveFilmCoefficientforWindowsinLowRiseBuildings.Pdf." 